$\mathrm{DE}$

M E D I C I N A

T R O P I C A L

$\mathrm{DE}$

SÃO PAULO

JOURNAL OF THE SÃO PAULO INSTITUTE OF TROPICAL MEDICINE

1 Universidade Federal de Minas Gerais, Hospital São Geraldo, Belo Horizonte, Minas Gerais, Brazil

${ }^{2}$ Universidade Federal de Minas Gerais, Faculdade de Medicina, Laboratório de Pesquisa em Micobactérias, Belo Horizonte, Minas Gerais, Brazil

${ }^{3}$ Universidade Federal de Minas Gerais, Faculdade de Medicina, Departamento de Oftalmologia e Otorrinolaringologia, Belo Horizonte, Minas Gerais, Brazil

Correspondence to: Silvana Spíndola de Miranda

Universidade Federal de Minas Gerais,

Faculdade de Medicina, Laboratório de Pesquisa em Micobactérias, Avenida Alfredo Balena, 190, CEP 301030-100, Belo Horizonte, MG, Brazil

Tel: +55 31999682825

E-mail: silvanaspindola@gmail.com

Received: 15 October 2019

Accepted: 10 December 2019

\section{Mycobacterium abscessus subsp. bolletii keratitis: rare case reported in Brazil}

\author{
Sabrina Cavaglieri Silva1, Isabela Neves de Almeida ${ }^{\left({ }^{2}\right.}$, Wesley Campos \\ Ribeiro ${ }^{3}$, Silvana Spíndola de Miranda ${ }^{\circledR 2}$, Anna Christina Higino Rocha
}

\section{ABSTRACT}

In this report, we described a rare case of Mycobacterium abscessus subsp. bolletii keratitis in a young healthy male, in the absence of risk factors.

KEYWORDS: hsp65-PRA. Hypopyon. Mycobacteria. Mycobacterium abscessus subsp. Bolletii keratitis. Ocular infection.

\section{INTRODUCTION}

Nontuberculous mycobacteria (NTM) are ubiquitous environmental microorganisms that can be recovered from environmental sources (soil, water) and are often found in man-made reservoirs ${ }^{1}$. These are pathogens that have the ability to form biofilms on organic and inorganic materials due to their resistance to disinfectants, antibiotics and heavy metals ${ }^{1}$.

The NTM can colonize, infect, cause disease, and are therefore, considered opportunistic pathogens that can cause disease when associated with risk factors, such as accidental or surgical trauma, ocular surface diseases, use of contact lenses, or immunosuppression ${ }^{1-4}$. They are divided into two major groups: 1) slow-growing NTM and 2) rapidly-growing NTM ${ }^{1,5}$.

Clinically, the most important slow-growing NTM are: Mycobacterium avium complex, Mycobacterium kansasii, Mycobacterium xenopi, Mycobacterium malmoense, Mycobacterium haemophilum, Mycobacterium genavense, Mycobacterium marinum, Mycobacterium szulgai, and Mycobacterium scrofulaceum. The most important rapidly-growing NTM are: Mycobacterium chelonae complex, Mycobacterium fortuitum complex, Mycobacterium abscessus (M. abscessus) and its subspecies ${ }^{1,5}$.

Some of the M. abscessus subspecies, such as M. abscessus subsp. abscessus, M. abscessus subsp. bolletii, and M. abscessus subsp. massiliense have been responsible for a wide variety of skin, soft tissue, ocular, and other serious infections, including widespread disease ${ }^{1}$. We report a rare case of Mycobacterium abscessus subsp. bolletii keratitis in a young healthy male, in the absence of risk factors.

\section{CASE REPORT}

A 37-year-old healthy male, who works as an industrial plumber, born and living in of Belo Oriente, Minas Gerais State, Brazil, visited the emergency department of Sao Geraldo Hospital, Federal University of Minas Gerais reporting an insidious hyperemia, intense photophobia and pain in the left eye for about 30 days. The 
patient reported no trauma, ocular foreign body, previous eye surgery, or use of contact lenses. He confirmed the appropriate use of personal protective equipment. During this period, he sought medical care at another service, and was medicated with retinol acetate eye ointment, amino acids, methionine and chloramphenicol (Regencel ${ }^{\circledR}$ ), followed by topical acyclovir (Zovirax $\left.{ }^{\circledR}\right)$, oral acyclovir (400 mg every $12 \mathrm{~h}$ ) associated with tobramycin eye drops, diclofenac sodium ophthalmic solution (Maxilerg ${ }^{\circledR}$ ), oral acetazolamide (Diamox ${ }^{\circledR}$ )and lubricant $\left(\right.$ Hyabak $\left.^{\circledR}\right)$. As there was no clinical improvement observed with the initial treatment, fungal keratitis was suspected and the treatment was then modified to topical pimaricin $(5 \%)$ and Vigamox ${ }^{\circledR}$ every $1 \mathrm{~h}$, and oral ketoconazole (200 mg every $12 \mathrm{~h}$ ).

Ocular examination showed 20/20 visual acuity (VA) in the right eye (RE) without correction, and of hand-eye coordination test in the left eye (LE). Normal biomicroscopy was observed in the RE, whereas the LE presented conjunctival hyperemia $(2+/ 4+)$ and cornea with a central infiltrate measuring $4.3 \times 4.0 \mathrm{~mm}$ associated with small satellite lesions, superimposed epithelial defect of $4.3 \times 3.5 \mathrm{~mm}$ and irregular borders, as well as $2+/ 4+$ corneal edema and wide anterior chamber, presence of whitish plaque in the lower endothelium measuring $3.0 \times 2.5 \mathrm{~mm}, 1 \mathrm{~mm}$ laminar hypopyon, and diffuse fibrin in the endothelium (Figure 1). Moreover, in the LE, increased bidigital tonometry was observed, and ultrasound revealed no significant changes in the posterior ocular segment.

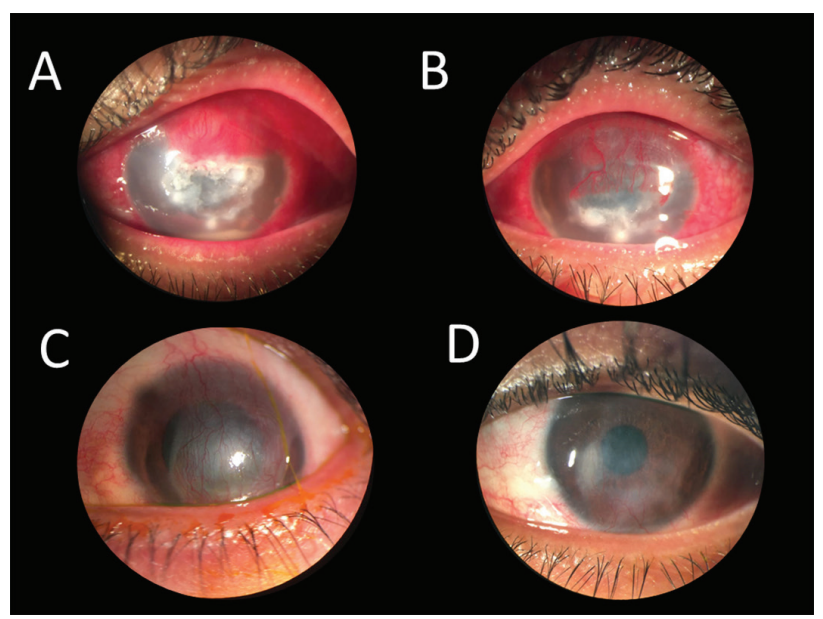

Figure 1 - Photographs of Mycobacterium abscessus subsp. bolletii keratitis clinical evolution: A) acute keratitis with presence of hypopyon; B) regression keratitis; C) leukoma with neovascularization; D) residual leukoma.

The patient was admitted to the hospital and corneal scraping was performed for bacterioscopy, bacterial culture, culture for fungi, bacilloscopy, culture for mycobacteria and for direct research techniques ${ }^{1}$. The patient was prescribed pimaricin $(5 \%)$ every $1 \mathrm{~h}$, acetazolamide $(250 \mathrm{mg})$ $\left(\right.$ Diamox $\left.^{\circledR}\right)$ every $6 \mathrm{~h}$, and atropine $(1 \%)$, timolol maleate $(0.5 \%)$, brimonidine tartrate $(0.2 \%)$, and oral ciprofloxacin (750 mg) every $12 \mathrm{~h}$. The laboratory findings showed negative results for bacterioscopy and bacilloscopy, positive bacteriological culture for Bacillus sp., negative assay and culture for fungi, and positive culture for mycobacteria. The bacterial colony, described as Bacillus $s p$ according to identification by Vitek $2^{\circledR}$, was atypical on blood agar and therefore, the material was cultivated in Lowestein Jensen solid medium, where the growth of characteristic mycobacterium colony was confirmed after visualization of acid-fast bacilli by Ziehl Neelsen staining. The organism was identified as Mycobacterium abscessus subsp. bolletii using the hsp65-PRA technique ${ }^{1}$.

For the treatment of NTM, the patient was prescribed ciprofloxacin hydrochloride $(3.5 \mathrm{mg} / \mathrm{g})$ ointment every $6 \mathrm{~h}$ and oral clarithromycin $(500 \mathrm{mg})$ every $12 \mathrm{~h}$ for 18 months, fortified vancomycin (2.5\%) eye drops for 4 months and fortified gentamicin (1.2\%) eye drops for 5 months. After 14 months of treatment, the result of conjunctival lavage culture for mycobacteria was negative. The patient showed progressive improvement, superior and inferior corneal neovascularization, hypopyon regression, reduction of infiltrate and edema with leukoma formation, epithelization and reduction of intraocular pressure, and 20/40 VA with pinhole for the LE at the end of the treatment (Figure 1).

\section{DISCUSSION}

Keratitis caused by NTM is an uncommon disease. Girgis et al. ${ }^{2}$ described an incidence of $36.6 \%$ for keratitis caused by M. abscessus/M. chelonae with the presence of biomaterials (63.1\%), eye surgeries (24.1\%), and exposure to corticosteroids (77\%), as risk factors.

Overall, the M. abcessus complex should be considered an agent of infectious keratitis, as well as a pathogen in nosocomial and pulmonary infections; the presence of Mycobacterium abscessus subsp. bolletii has been reported in pulmonary infections in patients with cystic fibrosis ${ }^{6-10}$. Another important characteristic of the M. abcessus complex (except for the subspecies massiliense) is the presence of macrolide-resistance inducing genes, mainly the erm, which can lead to poor treatment response ${ }^{10}$.

NTM keratitis manifests clinically as an indolent and chronic ulceration with the "cracked windshield" appearance of the cornea, around the central area of the infiltrate, and the lesions caused by these bacteria are important factors for diagnosis, but this is not commonly observed ${ }^{2,11}$. The most frequent symptoms of NTM keratitis are nonspecific: pain, photophobia, low visual acuity, foreign body sensation 
and irritation ${ }^{11}$. It can also present keratitis with irregular margins and satellite lesions or dendritic epithelial defect that simulates fungal or herpetic infections, respectively ${ }^{12}$. Consequently, failure of the initial diagnosis is frequent, as in our report, especially if there are no risk factors. However, despite the report of appropriate use of personal protective equipment, the occupational activity (plumber) might have caused exposure to various factors with micro-aerosols that contained infectious particles ${ }^{12}$.

There are some challenges related to the treatment due to poor penetration of the drugs, resistance to most conventional antimicrobials and the emergence of resistant strains, especially using monotherapy ${ }^{13}$, and because of the lack of consensus on the ideal therapeutic scheme in cases of NTM keratitis ${ }^{1,13}$. In this case, vancomycin and gentamicin were used in the fortified eye drops due to the fact that these drugs have been used for the last years in the treatment of keratitis caused by Mycobacterium abscessus subsp. bolletii and others of the M. abcessus complex ${ }^{14,15}$.

In this context, it is important to highlight that the synergism between vancomycin and clarithromycin to mycobacterial colonies of the M. abcessus complex has already been reported in in vitro studies, showing the importance of the association between vancomycin and clarithromycin in the same therapeutic regimen ${ }^{16}$. In general, for all M. abcessus complex infections, the treatment usually includes aminoglycosides and macrolide-based combination therapy, for weeks to months, followed by oral antimicrobial therapy $y^{4,17,18}$ and the guidelines of the American Thoracic Society and Infectious Diseases Society of America. They recommend different approaches for the treatment of extrapulmonary M. abcessus complex's infections, in general a total of 4-6 months of antibiotic therapy (macrolide-based antibiotic therapy such as clarithromycin) with at least 2 weeks of an initial combination of parenteral antibiotics is recommended, with a high likelihood of cure ${ }^{19,20}$. As we did not have the drug susceptibility test for the macrolide and there are different treatment times described in the literature, we chose the prolonged treatment (18 months $)^{1}$. It is important to point out that in this case the treatment occurred without any adverse reactions and was concluded with excellent outcome (cure, Figure 1D), even without the addition of corticosteroid.

\section{CONCLUSION}

The reported case supports the importance of testing for NTM in corneal ulcers that are difficult to control and do not respond to initial treatment, even in patients without risk factors.

\section{ACKNOWLEDGMENTS}

We are grateful to the Federal University of Minas Gerais (UFMG), to the Pro Rectory Research/UFMG, to the Brazilian Tuberculosis Network (REDE TB) and São Geraldo Hospital.

\section{CONFLICT OF INTERESTS}

The authors report no conflict of interests relevant to this article.

\section{ETHICAL APPROVAL}

The current case report integrates the project: "Evaluation of Laboratory Methods for identification and new nontuberculous mycobacteria susceptibility tests", approved by the Research Ethics Committee from the UFMG Ethics Committee protocol N ${ }^{\circ}$ CAAE: 93672218.8.0000.5149.

\section{FUNDING}

This research was funded by the Minas Gerais Research Support Foundation (FAPEMIG), process N $\mathrm{N}^{\circ} \mathrm{APQ}-03266-$ 13 and APQ-00094-12, and the National Research Council (CNPq), Process No 446796/2014 and 310174/2014-7.

\section{REFERENCES}

1. Forbes BA, Hall GS, Miller MB, Novak SM, Rowlinson MC, Salfinger M, et al. Practice guidelines for clinical microbiology laboratories: Mycobacteria. Clin Microbiol Rev. 2018;31:e00038-17.

2. Girgis DO, Karp CL Miller D. Ocular infections caused by non-tuberculous mycobacteria: update on epidemiology and management. Clin Exp Ophthalmol. 2012;40:467-75.

3. Gubler JG, Salfinger M, von Graevenitz A. Pseudoepidemic of nontuberculous mycobacteria due to a contaminated bronchoscope cleaning machine: report of an outbreak and review of the literature. Chest. 1992;101:1245-9.

4. Brown-Elliott BA, Nash KA, Wallace RJ. Antimicrobial susceptibility testing, drug resistance mechanisms, and therapy of infections with nontuberculous mycobacteria. Clin Microbiol Rev. 2012;25:545-82.

5. Brasil. Ministério da Saúde. Secretaria de Vigilância em Saúde. Departamento de Vigilância Epidemiológica. Manual nacional de vigilância laboratorial da tuberculose e outras micobactérias. Brasília: Ministério da Saúde; 2008.

6. Chehaibou I, Sandali O, Ameline B, Bouheraoua N, Borderie V, Laroche L. Bilateral infectious keratitis after small-incision lenticule extraction. J Cataract Refract Surg. 2016;42:626-30. 
7. Rollet-Cohen V, Roux AL, Le Bourgeois M, Sapriel G, El Bahri M, Jais JP, et al. Mycobacterium bolletii lung disease in cystic fibrosis. Chest. 2019;156:247-54.

8. Souto AS, Sabagh BP, Abreu AO, Silva SA, Pereira DC, Neves MC, et al. Tolerância de Mycobacterium abscessus subsp. bolletii a desinfetantes de alto nível. Rev Inst Adolfo Lutz. 2012;71:362-71.

9. Monteiro JT, Lima KV, Barretto AR, Furlaneto IP, Gonçalves GM, Costa AR, et al. Aspectos clínicos em pacientes com infecção pulmonar por micobactérias do complexo Mycobacterium abscessus na Amazônia brasileira. J Bras Pneumol. 2018;44:93-8.

10. Rubio M, March F, Garrigó M, Moreno C, Español M, Coll P. Inducible and acquired clarithromycin resistance in the mycobacterium abscessus complex. PLoS One. 2015;10:e0140166.

11. Kheir WJ, Sheheitli H, Abdul Fattah, Hamam RN. Nontuberculous mycobacterial ocular infections: a systematic review of the literature. Biomed Res Int. 2015;2015:164989.

12. Hu FR, Huang WJ, Huang SF. Clinicopathologic study of satellite lesions in nontuberculous mycobacterial keratitis. Jpn J Ophthalmol. 1998;42:115-8.

13. Gusmão FA, Alvarenga L, Barbosa L, Sampaio J, Leão SC, Hofling-Lima AL, et al. Deep stromal mycobacterial keratitis: viable bacteria after six months of treatment: case report and literature review. Arq Bras Oftalmol. 2005;68:551-3.
14. Wong R, Luo YH, Al-Zahawi MF, Poole TR. Infective crystalline keratopathy secondary to non-tuberculous mycobacterium (Mycobacterium abscessus) in a non-traumatized eye. Eye (Lond). 2007;21:1123-4

15. Giaconi JA, Pham R, Ta CN. Bilateral Mycobacterium abscessus keratitis after laser in situ keratomileusis. J Cataract Refract Surg. 2002;28:887-90.

16. Mukherjee D, Wu ML, Teo JW, Dick T. Vancomycin and clarithromycin show synergy against Mycobacterium abscessus in vitro. Antimicrob Agents Chemother. 2017;61:e01298-17.

17. Lee MR, Sheng WH, Hung CC, Yu CJ, Lee LN, Hsueh PR. Mycobacterium abscessus complex infections in humans. Emerg Infect Dis. 2015;21:1638-46.

18. Bostan C, Slim E, Choremis J, Boutin T, Brunette I, Mabon M, et al. Successful management of severe post-LASIK Mycobacterium abscessus keratitis with topical amikacin and linezolid, flap ablation, and topical corticosteroids. J Cataract Refract Surg. 2019;45:1032-5

19. Griffith DE, Aksamit T, Brown-Elliott BA, Catanzaro A, Daley C, Gordin F, et al. An official ATS/IDSA statement: diagnosis, treatment, and prevention of nontuberculous mycobacterial diseases. Am J Respir Crit Care Med. 2007;175:367-416.

20. Jeong SH, Kim SY, Huh HJ, Ki CS, Lee NY, Kang CI, et al. Mycobacteriological characteristics and treatment outcomes in extrapulmonary Mycobacterium abscessus complex infections. Int J Infect Dis. 2017;60:49-56. 